\begin{tabular}{|c|c|c|c|}
\hline \multirow{3}{*}{$\begin{array}{r}\text { Case Reports in } \\
\text { Gastroenterology }\end{array}$} & \multirow{2}{*}{\multicolumn{2}{|c|}{ Case Rep Gastroenterol 2016;10:605-612 }} & \multirow[b]{3}{*}{$\begin{array}{l}\text { Karger } \\
\text { Open access }\end{array}$} \\
\hline & & & \\
\hline & $\begin{array}{l}\text { DOI: 10.1159/000448064 } \\
\text { Publisned onine: Uctover 18, } 2016\end{array}$ & $\begin{array}{l}\text { (C) } 2016 \text { The Author(s) } \\
\text { Published by S. Karger AG, Basel } \\
\text { www.karger.com/crg }\end{array}$ & \\
\hline & $\begin{array}{l}\text { This article is licensed under the } \\
\text { International License (CC BY-NC) } \\
\text { Usage and distribution for commerci }\end{array}$ & $\begin{array}{l}\text { nons Attribution-NonCommercial } 4.0 \\
\text { ger.com/Services/OpenAccessLicense). } \\
\text { uires written permission. }\end{array}$ & \\
\hline
\end{tabular}

\title{
Hepatoid Carcinoma of the Pancreas: Case Report, Next-Generation Tumor Profiling, and Literature Review
}

\author{
James M. Chang ${ }^{a} \quad$ Nitin N. Katariya ${ }^{a} \quad$ Dora M. Lam-Himlin ${ }^{b}$ \\ Danielle J. Haakinson $^{a}$ Ramesh K. Ramanathan ${ }^{c}$ \\ Thorvardur R. Halfdanarson ${ }^{c}$ Mitesh J. Borad ${ }^{c}$ Rahul Pannala ${ }^{d}$ \\ Douglas Faigel $^{d} \quad$ Adyr A. Moss ${ }^{a}$ Amit K. Mathur ${ }^{a}$ \\ ${ }^{a}$ Division of Transplant and Hepatopancreatobiliary Surgery, Mayo Clinic Arizona, \\ Phoenix, Ariz., USA; ${ }^{b}$ Department of Laboratory Medicine and Pathology, Mayo Clinic \\ Arizona, Phoenix, Ariz., USA; ${ }^{C}$ Division of Hematology/Oncology, Mayo Clinic Arizona, \\ Phoenix, Ariz., USA; ${ }^{d}$ Division of Gastroenterology/Hepatology, Mayo Clinic Arizona, \\ Phoenix, Ariz., USA
}

\section{Keywords}

Hepatoid carcinoma $\cdot$ Pancreatic cancer

\begin{abstract}
Fewer than 25 cases of hepatoid carcinoma of the pancreas have been reported in the literature. We present a case in a 61-year-old male with a remote history of Hodgkin's lymphoma and gastric neuroendocrine cell hyperplasia. On surveillance endoscopic ultrasound, an $8 \times 5$ $\mathrm{mm}$ cystic lesion was seen in the tail of the pancreas. MRI showed a focal pancreatic duct cut-off with mild ductal dilation. Fine needle aspiration was performed, which was concerning for acinar cell carcinoma. The patient underwent distal pancreatectomy and recovered uneventfully. Final pathology demonstrated a $1.3-\mathrm{cm}$ hepatoid carcinoma of the pancreas, with a final clinicopathological stage of T1NOM0. Next-generation nucleic acid sequencing of the tumor did not suggest a viable adjuvant chemotherapeutic agent, and no adjuvant therapy was administered. The patient has no evidence of disease 6 months following resection.
\end{abstract}




\section{Case Reports in Gastroenterology}

Case Rep Gastroenterol 2016;10:605-612 DOI: 10.1159/000448064

C 2016 The Author(s). Published by S. Karger AG, Basel www.karger.com/crg

Chang et al.: Hepatoid Carcinoma of the Pancreas: Case Report, Next-Generation Tumor Profiling, and Literature Review

A further characterization and description of the outcomes of these rare tumors is warranted to help guide providers and counsel patients.

\section{Introduction}

Hepatoid carcinomas are carcinomas that appear histologically similar to hepatocellular adenocarcinomas. These rare neoplasms, and they may arise in a variety of extrahepatic sites, including the stomach, pancreas, lung, gallbladder, ovary, and colon [1-6]. The first case reported by Ishikura et al. [7] was of a gastric neoplasm with such characteristics. There appears to be a higher prevalence in gastric sites, which is thought to be due to the embryology of the foregut.

The diagnosis of hepatoid carcinoma is mainly histologic, with specimens showing features of abundant eosinophilic cytoplasm, finely granular cytoplasm, and intracytoplasmic hyaline globules, with a cellular morphology similar to hepatocellular carcinoma [8]. There is some question of whether these neoplasms arise from tumor transformation of native cells or ectopic nests of liver tissue, but in the absence of surrounding normal liver tissue, it may be assumed to be part of the malignant transformation process. Clinical signs of hepatoid carcinoma are few, though they may be associated with laboratory findings similar to those of hepatocellular carcinoma, such as elevated $\alpha$-fetoprotein (AFP) or PIVKA-II (protein induced by vitamin $\mathrm{K}$ absence/antagonist II) [1, 9-12]. In a review of 271 patients with hepatoid carcinomas of various anatomic origins, $84.8 \%$ of the patients demonstrated elevated AFP levels [13].

Hepatoid carcinoma has been considered to be a relatively high-grade, aggressive neoplasm when found in the stomach, with one review reporting liver metastases in 53 of 59 reported cases [1]. In patients with colonic neoplasms, there at least appears to be an association with inflammatory bowel disease [6]. In pancreatic hepatoid carcinoma, the incidence is not known, given the rarity of these tumors. Pancreatic hepatoid carcinoma may present as a solitary lesion or in conjunction with other pancreatic pathologies such as acinar adenocarcinoma, ductal adenocarcinoma, or neuroendocrine neoplasm. In the pancreas as well as in the stomach, hepatoid carcinoma is considered an aggressive malignancy warranting surgical resection if possible [14]. Given its rarity, there are no standard adjuvant therapies to prescribe, despite its high metastatic potential and poor prognosis.

Next-generation molecular profiling may have a use in such rare neoplasms, by searching for sites of possible susceptibility to standard adjuvant therapies. Von Hoff et al. [15] performed molecular profiling and treatment based on that molecular profiling on 66 patients with multiple tumor subtypes (breast, colorectal, ovarian, and multiple rare malignancies). The authors demonstrated the ability to measure molecular targets in patients' tumors as well as to find potential therapeutic targets, and they observed a longer progression-free survival among patients treated on the basis of their molecular profiling when compared to their prior therapy. Ang et al. [16] examined 350 hepatocellular carcinomas using a comprehensive multiplatform biomarker and identified a number of molecular targets with potential existing targeted therapies. While this technology is becoming more accessible and widespread, molecular targets have not thoroughly proven to be reliable indicators of in vivo response to therapy. Despite this caveat, with rare tumors, for which large clinical trials are not feasible, molecular profiling may represent a clinician's best attempt at an informed opinion about adjuvant therapies. 
Chang et al.: Hepatoid Carcinoma of the Pancreas: Case Report, Next-Generation Tumor Profiling, and Literature Review

Hepatoid carcinoma arising from the pancreas is a rare entity with a paucity of literature. We present a new case of this rare entity using next-generation molecular techniques.

\section{Case Report}

\section{Clinical Presentation}

A 61-year-old Caucasian male with a past medical history significant for a remote history of Hodgkin's lymphoma status post splenectomy, pernicious anemia, type 2 diabetes, hypertension, hyperlipidemia, hypothyroidism, gastric carcinoid tumors, and morbid obesity (BMI 47) presented with an anomalous pancreatic mass on endoscopic ultrasound (EUS). The patient had a 20-pack-year smoking history, having quit 5 years prior to presentation. The patient's diabetes had some sequelae of chronic renal insufficiency (creatinine 1.6 $\mathrm{mg} / \mathrm{dl}$ ), microalbuminuria, and moderate peripheral neuropathy secondary to vitamin $\mathrm{B}_{12}$ deficiency in the past. His perioperative hemoglobin $\mathrm{A}_{1 \mathrm{c}}$ level was $7.8 \%$.

EUS was being performed for surveillance of the nodular mucosa in the gastric fundus, of which biopsies revealed changes characteristic of autoimmune metaplastic atrophic gastritis including micronodular neuroendocrine cell hyperplasia. This study revealed an $8 \times 5$ $\mathrm{mm}$ anechoic cystic lesion in the pancreatic tail. Endoscopic sonographic findings were a simple cyst without septa or debris in close proximity to the pancreatic duct.

MRI of the abdomen showed a focal duct cut-off near the junction of the pancreatic body and tail with associated mild pancreatic ductal dilatation. Fine needle aspiration of the lesion obtained via EUS revealed cellular smears with variably sized groups of cells with round nuclei and abundant cytoplasm (fig. 1). Immunohistochemistry showed the tumor cells had membrane reactivity for $\beta$-catenin but no nuclear reactivity. Chromogranin and synaptophysin were nonreactive. Ki-67 immunostaining showed a proliferation index of 5-10\% (fig. 2). A diagnosis of acinar cell carcinoma of the pancreas was favored based on these findings.

\section{Surgical Course and Final Pathological Staging}

The patient was deemed a suitable surgical candidate, and he underwent an attempted laparoscopic distal pancreatectomy. However, given his morbid obesity and intra-abdominal adhesions the procedure was converted from a laparoscopic to a bilateral subcostal incision. It was then possible to mobilize the pancreas easily. The lesion itself was not palpable; however, based on preoperative imaging, the lesion was known to be $8 \mathrm{~cm}$ from the end of the tail of the pancreas. Approximately $15 \mathrm{~cm}$ of the pancreas were mobilized up to the level of the superior mesenteric vein. The pancreas was then divided along the midline with an Endo GIA stapler. The pancreatic stump was oversewn with a 4-0 Prolene suture in a locking fashion, and two 19-Fr Blake drains were left in the pancreatic bed. An intraoperative frozen section revealed negative margins. The patient did well postoperatively, his drains were removed, and he was discharged home in good condition on postoperative day 5. On final pathology, a $1.3-\mathrm{cm}$ malignant lesion was seen compressing the main pancreatic duct, composed of large epithelioid cells with abundant cytoplasm and frequent mitotic activity arranged in sheets and focal rosettes (fig. 3). Areas showed bile production by tumor cells, and a hepatocyte-specific antigen immunohistochemical stain was strongly positive (fig. 4). The final diagnosis was a hepatoid carcinoma involving the pancreatic body, confined to the parenchyma without extension into the peripancreatic adipose tissue and negative margins. The final clinicopathological stage was T1N0M0. 


\section{Case Reports in Gastroenterology}

Case Rep Gastroenterol 2016;10:605-612 DOI: $10.1159 / 000448064$

C 2016 The Author(s). Published by S. Karger AG, Basel www.karger.com/crg

Chang et al:: Hepatoid Carcinoma of the Pancreas: Case Report, Next-Generation Tumor Profiling, and Literature Review

\section{Next-Generation Tumor Profiling Results and Adjuvant Therapy Decision-Making}

The tumor tissue was further evaluated with high-throughput gene sequencing to evaluate for specific mutations that would warrant further adjuvant therapy. With Caris Molecular Intelligence ${ }^{\circledR} 600$ gene sequencing, the mutational analysis revealed two genes with known alterations. BAP1 is a BRCA1-associated protein and is a tumor suppressor gene that plays a role in protein deubiquitination metabolism and transcription regulation, as well as DNA damage repair. A Q590fs frameshift mutation in exon 14 was identified, and was thought to be pathological; it has been observed in melanoma, mesothelioma, renal cell carcinoma, and cholangiocarcinoma. Additionally, a presumed benign mutation was identified in NOTCH1, a protein in the Notch signaling cascade that regulates cell-cell interactions. The alteration was related to the rare single nucleotide polymorphism A1343V. In all, 37 of the genes tested had unclassified mutations based on current knowledge, and 16 genes had indeterminate results. No genetic alterations were identified in 539 genes, including 55 common genes associated with cancer, such as BRCA1, BRCA2, eGFR, c-KIT, JAK-2, Her2/Neu, KRAS, and several others. The genetic anomalies were mapped to potential adjuvant chemotherapeutic agents based on the current literature, but the tumor did not seem to have a genetic alteration pattern associated with a known benefit with adjuvant chemotherapy, albeit this approach has not been validated prospectively. The patient was not eligible for existing clinical trials. Adjuvant radiation therapy was deferred due to the negative nodal status, small tumor size, and negative surgical margins. In this context, the patient was followed with close clinical evaluation and surveillance imaging. At 6 months following resection, the patient had no evidence of disease and was clinically doing well with excellent functional status.

\section{Discussion}

Hepatoid carcinoma of the pancreas is a rare neoplasm with fewer than 25 cases reported in the literature. Typically defined as a neoplasm with features of hepatocellular carcinoma outside of the liver, hepatoid carcinoma has been found in multiple organs as a primary tumor $[1,7,17-19]$. Clinically, patients with hepatoid carcinoma are typically middle-aged to older, and may demonstrate higher serum AFP levels and nonspecific symptoms [20]. The tumors may arise as solitary primary tumors or in conjunction with neuroendocrine, acinar cell tumors, mucinous tumors of the pancreas, or ductal adenocarcinomas [21-25].

In prior reviews of cases of hepatoid carcinoma, patients had a mean age of 52.9 years with a slight male predominance $(62-63.6 \%)[8,14]$. Specific tumor histopathologies of hepatoid carcinoma with mixed subtypes (acinar, duct cell, mucin, neuroendocrine, and serous microcystic adenoma) when compared to pure hepatoid carcinoma found better survival and recurrence rates with the pure hepatoid pathology [26, 27]. There was no predominant location in the pancreas, and sizes ranged from 0.5 to $11 \mathrm{~cm}$. The majority of cases were clinically asymptomatic $(31.3 \%)$ or presenting with back or epigastric pain $(27.3 \%)$, jaundice (18.2\%), nausea/vomiting (18.2\%), or weight loss (13.6\%). Elevations in AFP were reported in 12 of 22 cases; however, for 3 cases, levels were not reported or assessed. While many hepatocellular carcinoma tumors express AFP at levels which may be detectable in serum, it is difficult to identify its role in hepatoid carcinoma of the pancreas. If preoperative elevations are found, it may be a useful marker for postoperative surveillance. However, the low incidence of this tumor makes it difficult to endorse the sensitivity of AFP as a screening test in pancreatic tumors. Eleven patients reviewed by Marchegiani et al. [14] had pathology 
consistent only with hepatoid carcinoma. Mixed histopathologies of hepatoid carcinoma included: neuroendocrine tumors $(n=6)$ and acinar $(n=1)$, ductal $(n=4)$, mucinous $(1)$, and serous microcystic adenoma $(\mathrm{n}=1)[8,14]$.

Hepatoid carcinoma of the pancreas has demonstrated heterogeneity in its prognosis, but overall it is considered to be an aggressive tumor [7]. Surgical resection remains the mainstay of therapy. Marchegiani et al. [14] found that of the 22 previous adult cases reported in the literature, $46 \%(\mathrm{n}=10)$ presented with distant metastases; yet $87 \%(\mathrm{n}=16)$ underwent surgery, and $41 \%(\mathrm{n}=9)$ died ( 5 of the 9 patients managed nonoperatively) after a mean survival of 18 months. Chemotherapy has been recommended given the metastatic potential of these tumors [20], though the selection of agents is variable and not evidence based and outcomes are largely unknown [25, 28]. Specific risk factors for poor prognosis are difficult to identify given the limited reporting of cases, but tumor size, the presence of positive lymph nodes, and metastases likely carry a worse prognosis. There has been speculation that pure hepatoid carcinoma may have a better prognosis than mixed-type hepatoid carcinoma with other associated tumor pathologies [27].

A unique feature of this case is the utilization of next-generation nucleic acid sequencing to help determine the nature of genetic mutations and help guide therapy. This is a promising approach for rare tumors; if these data are disseminated by clinicians or other investigators, it may lead to novel insights into diagnosis, the application of adjuvant therapy, and the treatment of advanced disease [15, 16, 29-31]. However, the sheer volume of genomic data on each tumor type carries with it the challenge of an appropriate interpretation of genetic mutations. Our case of hepatoid carcinoma is the first reported in the literature with specific genetic mutations identified from the tumor. This information enlightened our multidisciplinary discussion of the patient's case. We did not ultimately recommend adjuvant chemotherapy given our uncertainty about its potential benefit based on the BAP1 and NOTCH1 mutations identified.

We here present an additional case of hepatoid carcinoma of the pancreas, identified incidentally in the tail of the pancreas on EUS. Aggressive surgical resection was pursued and provided an excellent clinical outcome and favorable oncologic outcomes on short-term follow-up. As with most other pancreatic tumor types, and based on prior case reports of this entity, resection with negative margins likely carries a favorable prognosis; further surveillance will be required to monitor for recurrence. The outcomes described for this tumor type are poor, with a high rate of recurrence, but further studies on this phenomenon are warranted. The role of genetic sequencing and mutation identification in this tumor type remains largely unexplored, but a detailed characterization of these rare tumors may help delineate the utility of specific chemotherapeutic agents that could be applied in the adjuvant or neoadjuvant setting.

\section{Statement of Ethics}

The authors have no ethical conflicts to disclose.

\section{Disclosure Statement}

There are no potential conflicts of interest to disclose in association with this study. 
Chang et al.: Hepatoid Carcinoma of the Pancreas: Case Report, Next-Generation Tumor Profiling, and Literature Review

\section{References}

$\checkmark 1$ Roberts CC, Colby TV, Batts KP: Carcinoma of the stomach with hepatocyte differentiation (hepatoid adenocarcinoma). Mayo Clin Proc 1997;72:1154-1160.

2 Devi NR, Sathyalakshmi R, Devi J, Lilly SM: Hepatoid adenocarcinoma of the gall bladder - a rare variant. J Clin Diagn Res 2015;9:ED09-ED10.

-3 Søreide JA, Greve OJ, Gudlaugsson E, Størset S: Hepatoid adenocarcinoma of the stomach - proper identification and treatment remain a challenge. Scand J Gastroenterol 2016;51:646-653.

4 Motooka Y, Yoshimoto K, Semba T, Ikeda K, Mori T, Honda Y, et al: Pulmonary hepatoid adenocarcinoma: report of a case. Surg Case Rep 2016;2:1.

5 Liu XL, Wang X, Zhu FF: Hepatoid carcinoma of the ovary: a case report and review of the literature. Oncol Lett 2012;4:947-950.

-6 Chen Y, Schaeffer DF, Yoshida EM: Hepatoid adenocarcinoma of the colon in a patient with inflammatory bowel disease. World J Gastroenterol 2014;20:12657-12661.

7 Ishikura H, Fukasawa Y, Ogasawara K, Natori T, Tsukada Y, Aizawa M: An AFP-producing gastric carcinoma with features of hepatic differentiation. A case report. Cancer 1985;56:840-848.

-8 Steen S, Wolin E, Geller SA, Colquhoun S: Primary hepatocellular carcinoma ('hepatoid' carcinoma) of the pancreas: a case report and review of the literature. Clin Case Rep 2013;1:66-71.

-9 Senzaki H, Kiyozuka Y, Mizuoka H, Yamamoto D, Ueda S, Izumi H, et al: An autopsy case of hepatoid carcinoma of the ovary with PIVKA-II production: immunohistochemical study and literature review. Pathol Int 1999;49:164-169.

10 Matsueda K, Yamamoto H, Yoshida Y, Notohara K: Hepatoid carcinoma of the pancreas producing protein induced by vitamin K absence or antagonist II (PIVKA-II) and $\alpha$-fetoprotein (AFP). J Gastroenterol 2006;41:1011-1019.

11 Wincewicz A, Kowalik A, Zieba S, Lewitowicz P, Góźdź S, Sulkowski S: $\alpha$-Fetoprotein-producing hepatoid gastric adenocarcinoma with osteoclast-like giant cells and neuroendocrine differentiation: a case study with molecular profiling. Int J Surg Pathol 2015;23:537-541.

12 Plaza JA, Vitellas K, Frankel WL: Hepatoid adenocarcinoma of the stomach. Ann Diagn Pathol 2004;8:137-141.

13 Su JS, Chen YT, Wang RC, Wu CY, Lee SW, Lee TY: Clinicopathological characteristics in the differential diagnosis of hepatoid adenocarcinoma: a literature review. World J Gastroenterol 2013;19:321-327.

14 Marchegiani G, Gareer H, Parisi A, Capelli P, Bassi C, Salvia R: Pancreatic hepatoid carcinoma: a review of the literature. Dig Surg 2013;30:425-433.

15 Von Hoff DD, Stephenson JJ Jr, Rosen P, Loesch DM, Borad MJ, Anthony S, et al: Pilot study using molecular profiling of patients' tumors to find potential targets and select treatments for their refractory cancers. J Clin Oncol 2010;28:4877-4883.

16 Ang C, Miura JT, Gamblin TC, He R, Xiu J, Millis SZ, et al: Comprehensive multiplatform biomarker analysis of 350 hepatocellular carcinomas identifies potential novel therapeutic options. J Surg Oncol 2016;113:55-61.

17 Mokrim M, Belbaraka R, Allaoui M, Kairaouani M, Mahassini N, Tahri A, et al: Hepatoid adenocarcinoma of the lung: a case report and literature review. J Gastrointest Cancer 2012;43(suppl 1):S125-S127.

18 Mazouz A, Amaadour L, Ameurtesse H, Chban L, Amarti A, Kettani F, et al: Primary hepatoid carcinoma of the ovary: a case report. Pan Afr Med J 2015;20:93.

19 Slotta JE, Jüngling B, Kim YJ, Wagner M, Igna D, Schilling MK: Hepatoid adenocarcinoma of the transverse colon. Int J Colorectal Dis 2012;27:989-991.

20 Hameed O, Xu H, Saddeghi S, Maluf H: Hepatoid carcinoma of the pancreas: a case report and literature review of a heterogeneous group of tumors. Am J Surg Pathol 2007;31:146-152.

21 Tanno S, Obara T, Fujii T, Izawa T, Mizukami Y, Saitoh Y, et al: $\alpha$-Fetoprotein-producing adenocarcinoma of the pancreas presenting focal hepatoid differentiation. Int J Pancreatol 1999;26: 43-47.

22 Yano T, Ishikura H, Wada T, Kishimoto T, Kondo S, Katoh H, et al: Hepatoid adenocarcinoma of the pancreas. Histopathology 1999;35:90-92.

-23 Cuilliere P, Lazure T, Bui M, Fabre M, Buffet C, Gayral F, et al: Solid adenoma with exclusive hepatocellular differentiation: a new variant among pancreatic benign neoplasms? Virchows Arch 2002;441:519-522.

24 Wang H, Wang X, Ju Y, Wang J, Zhang X, Cheng Y, et al: Clinicopathological features and prognosis of pseudomyxoma peritonei. Exp Ther Med 2014;7:185-190.

25 Lam K, Lo C, Wat M, Fan ST: Malignant insulinoma with hepatoid differentiation: a unique case with alpha-fetoprotein production. Endocr Pathol 2001;12:351-354.

26 Hughes K, Kelty S, Martin R: Hepatoid carcinoma of the pancreas. Am Surg 2004;70:1030-1033.

-27 Kelly PJ, Spence R, Dasari BV, Burt AD, Taylor M, Loughrey MB: Primary hepatocellular carcinoma of the pancreas: a case report and review of the heterogeneous group of pancreatic hepatoid carcinomas. Histopathology 2012;60:1012-1015. 


\section{Case Reports in \\ Gastroenterology}

\begin{tabular}{l|l}
\hline Case Rep Gastroenterol 2016;10:605-612 \\
\hline DOI: 10.1159/000448064 & $\begin{array}{l}\text { @ 2016 The Author(s). Published by S. Karger AG, Basel } \\
\text { www.karger.com/crg }\end{array}$ \\
\hline
\end{tabular}

Chang et al:: Hepatoid Carcinoma of the Pancreas: Case Report, Next-Generation Tumor Profiling, and Literature Review

28 Paner GP, Thompson KS, Reyes CV: Hepatoid carcinoma of the pancreas. Cancer 2000;88:1582-1589.

29 Takai E, Yachida S: Genomic alterations in pancreatic cancer and their relevance to therapy. World J

Gastrointest Oncol 2015;7:250-258.

-30 Tsimberidou AM, Iskander NG, Hong DS, Wheler JJ, Falchook GS, Fu S, et al: Personalized medicine in a phase I clinical trials program: the MD Anderson Cancer Center initiative. Clin Cancer Res 2012;18:6373-6383.

-31 Jiao Y, Yonescu R, Offerhaus G, Klimstra DS, Maitra A, Eshleman JR, et al: Whole-exome sequencing of pancreatic neoplasms with acinar differentiation. J Pathol 2014;232:428-435.

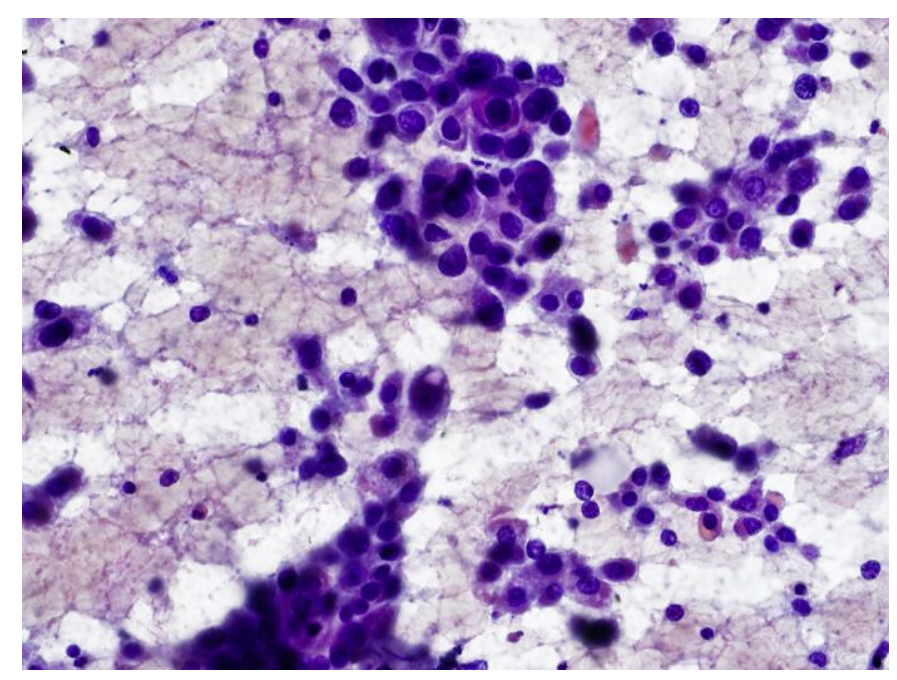

Fig. 1. Cytology of pancreatic mass obtained via fine needle aspiration on EUS. The fine needle aspirate of the tumor showed clusters of malignant epithelioid cells with marked nuclear variation. Pap stain. Original magnification, $\times 40$.

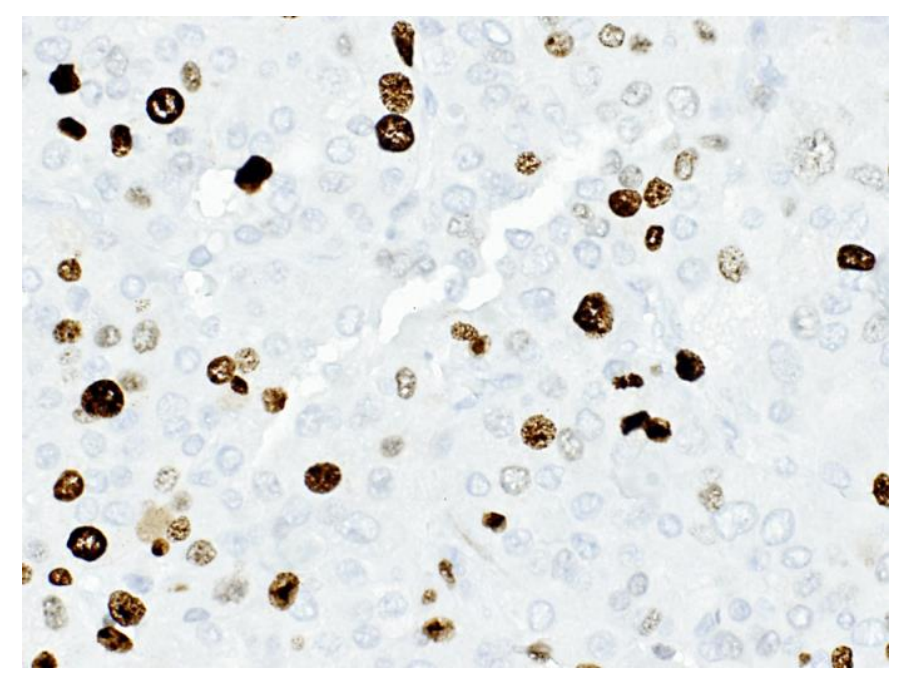

Fig. 2. Hepatoid carcinoma of the pancreas. Ki-67 immunostaining showed a proliferation index of 5-10\%. 


\section{Case Reports in \\ Gastroenterology}

\begin{tabular}{l|l}
\hline Case Rep Gastroenterol 2016;10:605-612 \\
\hline DOI: 10.1159/000448064 & $\begin{array}{l}\text { @ 2016 The Author(s). Published by S. Karger AG, Basel } \\
\text { www.karger.com/crg }\end{array}$ \\
\hline
\end{tabular}

Chang et al.: Hepatoid Carcinoma of the Pancreas: Case Report, Next-Generation Tumor Profiling, and Literature Review

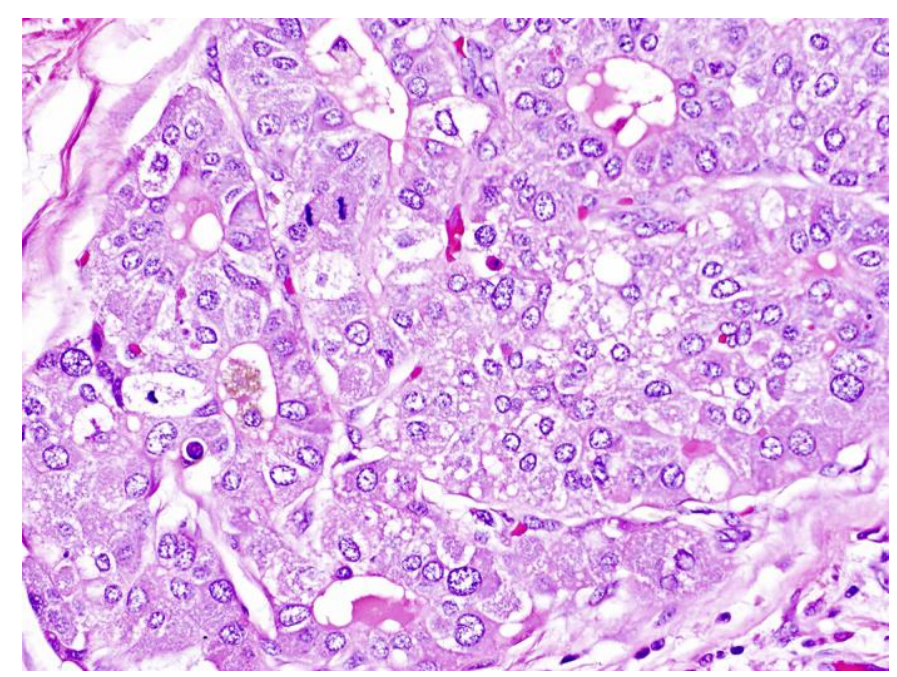

Fig. 3. Hepatoid carcinoma of the pancreas. The resection specimen showed sheets and cords of tumor cells with abundant eosinophilic cytoplasm, large irregular nuclei, frequent mitoses, and occasional rosette formation. Hematoxylin and eosin. Original magnification, $\times 400$.

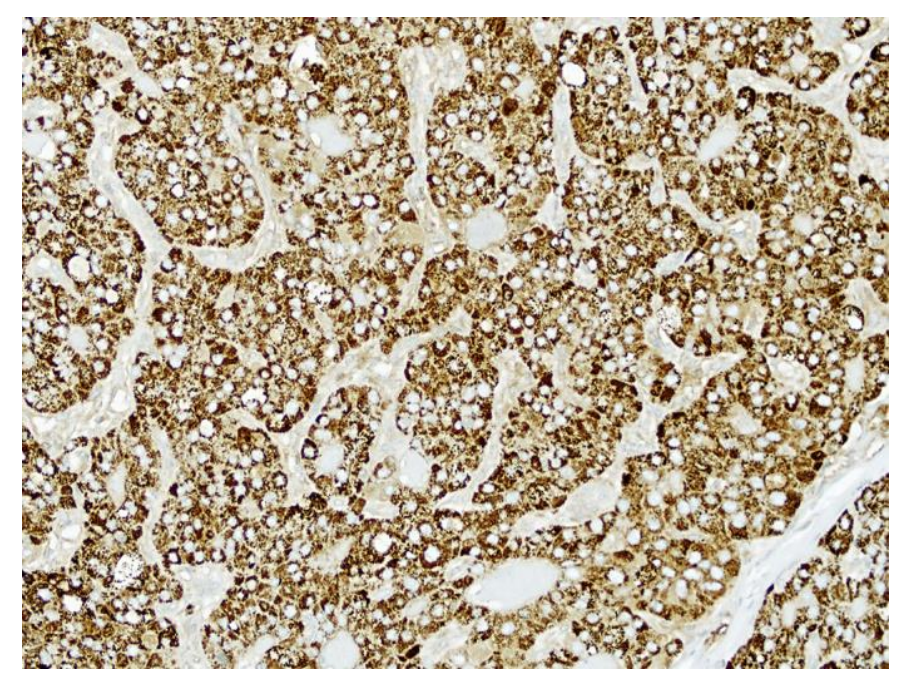

Fig. 4. Hepatoid carcinoma of the pancreas. The tumor cells are strongly and diffusely reactive for hepatocyte-specific antigen by immunohistochemical staining. Hepatocyte-specific antigen immunostain. Original magnification, $\times 200$. 